\title{
O EFFITO DA UTILIZAÇÃO DO BRINQUEDO TERAPEUTICO, PELA ENFERMEIRA PEDIATRA, SOBRE O COMPORTAMENTO DE CRIANÇAS RECÉM-HOSPITALIZADAS *
}

\author{
Circéa Amalia Ribeiro**
}

RIBEIRO, C.A. O efeito da utilização do brinquedo terapêutico, pela enfermeira pediatra, sobre o comportamento de crianças recém-hospitalizadas. Rev. Esc. Enf. $U S P$, v. 25 , n. 1, p. 41-60, abr. 1991.

$O$ trabalho descreve a realização e os resultados de uma pesquisa experimental, executada entre crianças de 3 a 5 anos, recém-hospitalizadas, com utilização da técnica de brinquedo terapêtutico. Os resultados demonstram que ela favoreceu o aparecimento de comportamentos mais campativeis ao desenvolvimento esperado da criança nesta faixa etária, assim como os considerados de adaptação ou do ego forte.

UNITERMOS: Brinquedo. Criança hospitalizada. Enfermagem pediátrica.

\section{I - INTRODUÇĀO}

Sabe-se, através de trabalhos realizados por vários autores, o que tenho comprovado na prática profissional, que a hospitalização constitui uma experjência altamente estressante e traumática para a criança, com reflexo no seu comportamento durante a permanência no hospital e mesmo após a alta.

A sensação de abandono decorrente da separação da mãe, a inscgurança causada pelo ambiente estranho, a condição física desfavorável da criança, a sensação de perda de controle por não poder praticar habilidades já desenvolvidas, 0 fato dela imaginar muitas vezes que está sendo punida, a falta de estimulação sensorial, de cuidados prestados carinhosamente e de contato físico íntimo com outro ser humano são importantes fontes de ansiedade $e$ tensão emocional para a criança hospitalizada e segundo MARLOW ${ }^{16}$ podem fazer com que a criança fique traumatizada em maior grau do que está fisicamente doente. MACHADO \& MACHADO ${ }^{15}$ nos lembram que, em alguns casos as reações à hospitalização podem agravar ou se confundir com os sintomas da própria doença, dificultando o diagnóstico e o tratamento. Diversas reco-

- Resumo de Dissertacăo de Mestrado upresenatda em 1986, à Escola de Enfermagem da Universidade de Săo Paulo.

** Enfermeira. Mestre em Enfermagem Pediátrica, Professor Assistente do Departamento de Enfermagem Materno-Infantil e Psiquiatria da Universidade Federal Fluminense, Disciplinas: Enfermagem Materno-Infantil e Enfermagem Pedlátrica Médico-Cirúrgica. 
mendações têm sido feitas ROBERTSON ${ }^{25}$, MACHADO \& MACHADO ${ }^{15}$, PRUGH ${ }^{22}$, BARTON ${ }^{2}$, MORAES ${ }^{19,20}$, KENNY $^{12}$, KUM \& ILGEN ${ }^{13}$, WHALEY \& WONG ${ }^{27}$, RAMSEY ${ }^{23}$, para que os efeitos da hospitalização sobre a criança sejam minimizados, entre as quais: permitir a permanência dos pais no hospital, evitar o rodízio do pessoal que cuida da criança, prepará-la para a hospitalização, os procedimentos e tratamentos, utilizar o brinquedo na assistência à criança.

Brincar, de acordo com SABOYA ${ }^{26}$, deriva da palavra brinco, que vem do latim vínculo cujo significado é fazer lagas, ligar-se. Esta definição etimológica da palavra já demonstra o quanto a atividade lúdica é essencial ao desenvolvimento infantil, ou seja, é brincando que, desde bebê, a criança se lìga às pessoas e ao meio ambiente.

O brinquedo é, pois, uma importante atividade da infância e deve ser considerado não só como uma forma de diversão e entretenimento, mas sim como o trabalho da criança, o meio pelo qual ela se desenvolve emocionalmente, socialmente e intelectualmente de forma natural. Por isso, para a criança hospitalizada, que continua sendo criança, e deve continuar a se desenvolver, ele é de primordial importância, sendo seu uso preconizado na assistência em geral, e especificamente na assistência de enfermagem, inclusive sob as diferentes formas do brinquedo terapêutico.

\section{E o que é o brinquedo terapêutico?}

Sabe-se que além de recreação e estimulação, uma importante função do brinquedo é a dramatização de papéis, de conflito e a catar-se MACHADO ${ }^{14}$. Graças a ela, além de possibilitar o diagnóstico de um conflito que a criança esteja vivenciando, o brinquedo tem também função curativa, pois funciona como uma "válvula de escape", conduzindo à diminuição da ansiedade. Esta última função constitui a base da ludoterapia, técnica de psicoterapia infantil e também do brinquedo terapêutico, que utiliza princípios de ludoterapia.

GREEN 9, para melhor esclarecer aos enfermeiros, diferencia ludoterapia de brinquedo terapêutico:

- Ludoterapia: técnica psiquiátrica usada para tratamento de crianças com distúrbios emocionais, neuróticas ou psicóticas, realizada em sessões conduzidas por psiquiatra, psicólogo ou enfermeira psiquiatra, sendo o meio ambiente muito bem controlado. Sua meta é promover a compreensão, pela criança, de seus próprios comportamentos e sentimentos. O terapeuta reflete à criança suas expressões verbais e não verbais e as interpreta para ela. Normalmente as sessões levam de meia a uma hora e podem se estender por vários meses.

- Brinquedo terapêtico: técnica que pode ser usada por qualquer enfermeiro, para qualquer criança hospitalizada, com o objetivo de permitir à enfermeira alguma compreensão das necessidades e sentimentos da criança. Assim, refletem-se à criança apenas 
suas expressões verbais e não se interpretam suas atividades. As sessões podem ser realizadas na sala de brinquedos do hospital, na cama da criança, ou em qualquer outra área conveniente e levam de 15 a 45 minutos.

Para WOLTMAN ${ }^{28}$, entretanto, o brinquedo terapêutico tem por si mesmo um grande valor catártico para a criança, mesmo sem a participação verbal do terapeuta.

BARTON $^{2}$ e CLATWORTH ${ }^{4}$ colocam que o brinquedo terapêutico é também a utilização de uma brincadeira simulondo situações hospitalares, obedecendo os princípios de ludoterapia, porém de uma forma mais dirigida, onde a criança receberá explicações sobre os procedimentos a que deve ser submetida, ou descarregará sua tensão após os procedimentos, visualizando as situações e manuseando os instrumentos e suas imitações. Recomendam ainda, como vários outros autores, que o brinquedo terapêutico seja parte integrante da assistência de enfermagem.

$\mathrm{Na}$ literatura de enfermagem há vários trabalhos, entre os quais os de ERICKSON ${ }^{6}$, BARTON $^{2}$, GREEN ${ }^{10}$, CLATWORTH ${ }^{4}$, MORAES et al. ${ }^{21}$, MARTINS et alii ${ }^{17},{ }^{18}$, RIBEIRO ${ }^{24}$, que demonstram os beneficios da utilização desta técnica junto à criança hospitalizada. Neste trabalho, resolvi utilizá-lo junto a crianças recém-hospitalizadas, e portunto vivendo uma situação altamente estressante e verificar qual o seu efeito sobre o comportamento dessas crianças, no sentido de comprovar se ele é um instrumento efetivo a ser utilizado pelos enfermeiros que desejam auxiliá-las a enfrentarem esta situação.

\section{II - OBJETIVO:}

Verificar a influência da utilização do brinquedo terapêutico, pela enfermeira, sobre o comportamento de crianças de 3 a 5 anos de idade, recém-hospitalizadas, no primeiro ou segundo dia após a internação.

\section{III - METODOLOGIA}

A coleta de dados foi realizada em três instituições hospitalares da cidade de São Paulo, durante três anos e dois ıneses.

A amostra foi constituída de 22 crianças de 3 a 5 anos de idade, de ambos os sexos, que estavam sendo internadas pela primeira vez, no primeiro ou segundo dia após a admissão, com diagnósticos diversos (a grande maioria portadora de problemas respiratórios), com temperatura corpórea normal ou levemente desviada do normal (até $37,2^{\circ} \mathrm{C}$ ), sendo seu estado clínico geral considerado não grave, e em condições de brincar, ou seja, acordadas e contatuando com o meio ambiente.

As crianças foram, altcrnadamente, conforme sua acimissão na unidade, divididas em 2 grupos de estudo, Experimental e Controle. Foram feitas, por mim mesma, duas observações de comportamento de $10 \mathrm{mi}$ - 
nutos cada, de cada uma das crianças de ambos os grupos: a primeira, pela manhã, foi chamada de situação anterior e a segunda, à tarde do mesmo dia, chamada de situação posterior.

Para as crianças do grupo experimental, imediatamente após a observação do comportamento na situação anterior, foi realizada uma sessão individual de brinquedo terapêutico (ou entrevista com brincadeira), junto a mim, no caso a enfermeira pesquisadora, durante $45 \mathrm{mi}$ nutos e descrito seu comportamento. As crianças do grupo controle não participavam de sessão de brinquedo terapêutico.

Esta sessão foi realizada dentro da enfermaria, no leito da criança, obedecendo aos princípios básicos da técnica descritos por AXLINE ${ }^{1}$, ERICKSON ${ }^{6}$, GREEN $^{9}$ e sucedia da seguinte maneira: terminada a observação de seu comportamento, na situação anterior, eu me aproximava da criança e a convidava para brincar, dizendo que lhe emprestaria alguns brinquedos, com os quais ela poderia brincar por algum tempo, como quisesse, mas que teria de devolvê-los quando eu fosse embora, e que enquanto ela brincasse, eu iria escrever. Durante a sessão de brinquedo terapêutico, permanecia próxima à criança, sem interferir na brincadeira; participava somente quando a criança solicitava, por exemplo, para auxiliar a despir ou vestir alguma boneca, responder o nome de algum brinquedo, ou assistí-la na satisfação de alguma necessidade fisiológica. Sempre que a criança perguntava sobre algo, como do que, ou, com o que brincar, devolvia-lhe a pergunta, no sentido de garantir que todas as decisões a respeito da brincadeira fossem tomadas por ela. Ao terminar o tempo, avisava à criança que iria embora e lhe pedia que me auxiliasse a guardar os brinquedos. A seguir, despedia-me e saia levando os mesmos.

Os brinquedos utilizados na sessão de brinquedo terapêutico (anexo I) foram: bonecos de pano caracterizando médico, enfermeira, pai, mãe e crianças; material hospitalar como termômetro, seringa, estetoscópio, espátula; utensílios domésticos como pratinhos, panelinhas, mamadeira; carrinho, telefone, revolver; blocos de madeira de diferentes formas geométricas; papel e lápis de cor. Material assim variado é preconizado por JUNKER ${ }^{11}$ apud GREEN ${ }^{11}$, para que a criança possa expressar diferentes sentimentos, dramatizar situações domésticas e hospitalares e seu uso é descrito em trabalhos de outros autores.

Os comportamentos observados eram registrados em folha com local destinado à identificação da criança e colunas próprias para registrar: o tempo, o comportamento da criança observada, o comportamento de pessoas que interagiam com a criança a a categorização dos comportamentos da mesma.

Após a coleta dos dados, os comportamentos apresentados pelas crianças nas situaçōes anterior e posterior, foram listados, agrupados e categorizadus, com base na descrição do universo dos comportamentos e respostas comportamentais apresentadas pelas próprias crianças observadas nos 2 grupos de estudo. O comportamento da criança, durante a 
sessão de brinquedo terapêutico, aqui considerada o instrumento de intervenção de enfermagem, não foi estudado neste trabalho.

As categorias encontradas foram:

1. Categorias de comportamentos * quanto às interações interpessoais (divisão do comportamento total nas situações anterior e posterior):

- comportamento sem interação interpessoal

- comportamento com interação interpessoal

- iniciada pela criança

- iniciada por outra pessoa

- que não se sabe por quem foi iniciada, por já estar acontecendo ao início da observação.

2. Categorias de respostas comportamentais" (divisão dos comportamentos de interação em unidades menores) conforme o tipo de atividade que a criança realizava: movimentar-se, olhar, expressar emoções, verbalizar, brincar e não responder a um estimulo ou solicitação. A categoria movimentar-se englobou as seguintes sub-categorias: movimenta partes do corpo, muda de posição, manipula partes do corpo, manipula roupa ou objetos, contorna ou bate em objetos do meio ambiente com outro objeto, suga, morde, apoia-se em alguém, movimenta-se relativamente a funçōes fisiologicas, anda dentro de berço, desloca-se no meio ambiente (podendo ser: sem finalidade aparente, com finalidade aparente, ou seguindo alguém), realiza uma ação e fica parada.

3. Categorias relativas aos niveis de respostas comportamentais*, de acordo com a forma com que as crianças realizavam as diferentes atividades: Nivel I, Nivel II e Nivel III, conforme pareciam indicar, respectivamente, uma progressão positiva do comportamento da criança. Cada categoria de respostas comportamentais podia apresentar os vários níveis, exceto as categorias brincar, que só podia ser de Nível III, e não responder a um estímulo ou solicitação, que só podia ser de Nível I.

Em seguida foi realizada uma comparação da freqüência dos comportamentos e respostas comportamentais, nas duas situações de observação (anterior e posterior), dentro do mesmo grupo de estudo e entre os dois grupos.

\section{III - RESULTADOS E DISCUSSÃO}

De acordo com a tabela 1 vemos que, nos dois grupos de estudo há uma diminuição da porcentagem de comportamentos sem interação interpessoal e um aumento da de comportamentos com interação inter-

\footnotetext{
- Na dissertaç̃o original encontram-se descritos detalhadamente cada uma das categorias de comportamentos, respostas comportamentais e nivels de respostas comportamentals aquil cltados.
} 
pessoal. Porém, esta variação é maior entre as crianças do grupo experimental $(19,29 \%$ de diferença) do que entre as do grupo controle $(9,77 \%$ de diferença $)$.

T A B L A 1

PORCENTAGEM DOS COMPORTAMENTOS DAS CRIANÇAS DOS GRUPOS EXPERIMEINTAL E CONTROLE, QUANTO A INTERAÇAO

INTERPESSOAL, NAS SITUAÇOES ANTERIOR E POSTERIOR

\begin{tabular}{|c|c|c|c|c|}
\hline \multirow{4}{*}{$\begin{array}{l}\text { Comportamentos } \\
\text { Quanto à interaça }\end{array}$} & \multicolumn{4}{|c|}{ Grupos } \\
\hline & \multicolumn{2}{|c|}{ Experimental } & \multicolumn{2}{|c|}{ Controle } \\
\hline & \multirow[b]{2}{*}{ Anterior } & \multicolumn{2}{|c|}{ Situaça } & \multirow[b]{2}{*}{ Posterior } \\
\hline & & Posterior & Anterior & \\
\hline Sem interação & 48,24 & 28,95 & 52,27 & 42,50 \\
\hline Com Interação & 51,76 & 71,05 & 47,73 & 57,50 \\
\hline Total & 100,00 & 100,00 & 100,00 & 100,00 \\
\hline
\end{tabular}

T A B ELA 2

PORCENTAGEM DOS TIPOS DE COMPORTAMENTOS D E INTERAÇAO INTERPESSOAL, DAS CRIANÇAS DO GRUPO EXPERIMENTAL E CONTROLE, NAS SITUAÇBES ANTERIOR E POSTERIOR

\begin{tabular}{|c|c|c|c|c|}
\hline \multirow[b]{2}{*}{$\begin{array}{l}\text { Comportamemtos de } \\
\text { Interagato Interpessoal }\end{array}$} & Exparimental & \multicolumn{3}{|c|}{ Grupos } \\
\hline & Interior & $\begin{array}{r}\text { Sit } \\
\text { Posterior }\end{array}$ & Anterior & Posterior \\
\hline $\begin{array}{l}\text { Iniciados pela criança } \\
\text { Iniciados por outro } \\
\text { Iniciados por alguém } \\
\text { que não se pode } \\
\text { identificar }\end{array}$ & $\begin{array}{l}75,00 \\
25,00\end{array}$ & $\begin{array}{c}81,48 \\
9,26\end{array}$ & $\begin{array}{l}76,19 \\
21,43\end{array}$ & $\begin{array}{l}63,04 \\
36,96\end{array}$ \\
\hline Total & 100,00 & 100,00 & 100,00 & 100,00 \\
\hline
\end{tabular}

* Corresponde ao primeiro comportamento observado em 5 crianças.

* Corresponde ao primeiro comportamento observado em 1 criança.

Através da tabela 2 verificamos que, na situação posterior, para as crianças do grupo experimental há um acréscimo da porcentagem de freqüência dos comportamentos de interação interpessoal iniciados pela criança e um decréscimo dos iniciados por outra pessoa, indicando que as crianças deste grupo passam não só a interagirem mais, como também a iniciarem mais as interações. Entre as crianças do grupo controle ocorre o inverso, mostrando que o aumento de comportamentos com interação interpessoal deve-se ao fato de outras pessoas iniciarem mais interações com elas. 
TABEL A 3

FREQUENCLA DE RESPOSTAS COMPORTAMENTAIS DAS CRIANÇAS OBSERVADAS, NAS SITUAÇÖES ANTERIOR E POSTERIOR

\begin{tabular}{|c|c|c|c|c|c|c|c|}
\hline \multirow{3}{*}{$\begin{array}{l}\text { Kespostas } \\
\text { Comportamentais }\end{array}$} & \multicolumn{6}{|c|}{ Situagão } & \\
\hline & \multicolumn{2}{|c|}{ Anterior } & \multicolumn{2}{|c|}{ Posterior } & \multicolumn{2}{|c|}{ Total } & \\
\hline & $\mathbf{N}^{9}$ & $\%$ & $\mathbf{N e}$ & $\%$ & $\mathbf{N e}^{-}$ & $\%$ & \\
\hline Olhar & 135 & 21,23 & 124 & 19,44 & 259 & $20,33)$ & \\
\hline Movimentar-se & 405 & 63,68 & 318 & 49,83 & 723 & $56,75\}$ & 77,08 \\
\hline Expressar emoçð̃es & 48 & 7,55 & 46 & 7,21 & 94 & 7,38 & \\
\hline Verbalizar & 38 & 5,97 & 69 & 10,82 & 107 & 8,40 & \\
\hline Brincar & - & - & 71 & 11,13 & 71 & $\mathbf{5 , 5 7}$ & \\
\hline $\begin{array}{l}\text { Não responder a um estí- } \\
\text { mulo ou solicitação }\end{array}$ & 10 & 1,57 & 10 & 1,57 & 20 & 1,57 & \\
\hline Tot al & 636 & $\begin{array}{r}100,00 \\
49,92\end{array}$ & 6,38 & $\begin{array}{r}100,00 \\
50,08\end{array}$ & 1.274 & 100,00 & \\
\hline
\end{tabular}

A tabela 3 mostra que, nos 20 minutos de observação, isto é: 10 minutos referentes à situação anterior e 10 minutos referentes à situação posterior, as crianças apresentaram um total de 1.274 respostas comportamentais. Mostra também que a maioria delas $(56,75 \%)$ pertence à categoria movimentar-se, seguida da categoria olhar $(20,33 \%)$, que juntas somam $77,08 \%$ das respostas comportamentais apresentadas pelas crianças de ambos os grupos, as demais categorias aparecem numa freqüência muito menor.

Conforme a tabela 4 vemos que, na situação posterior, entre as crianças do grupo experimental, em todas as categorias de respostas comportamentais, diminui o número de crianças que apresentam respostas comportamentais de Nivel I e Nível II e aumenta o número das que apresentam respostas comportamentais de Nivel III; e que as variações dessa freqüência são bastante significativas.

No grupo controle, as variações de freqüência não são muito acentuadas, observando-se aumento de frequiência de Nivel III, na situação posterior, apenas na categoria brincar, sendo este aumento de somente uma (1) criança.

De acordo com a tabela 5 vemos que a maior freqüência de respostas comportamentais apresentadas pelas crianças do grupo experimental, na situação anterior, refere-se à Subcategoria muda de posição, seguida por fica parada, e movimenta partes do corpo, todas no Nivel I, enquanto na situação posterior a Subcategoria que apresenta maior freqüência é realiza uma ação, no Nivel III, seguida por mudança de posição e movimenta partes do corpo, ambas no Nivel I. No total, entre as duas situações, anterior e posterior, há um decréscimo de freqüência nos Níveis I e II e um acréscimo significativo ao Nível III. 
T A BELA 4

FREQUENCIA DAS CRIANCGAS DOS DOIS GRUPOS, QUANTO AOS NIVEIS, DENTRO DAS CATEGORIAS DE RESPOSTAS COMPORTAMENTAIS, NAS STTUAÇOES ANTERIOR E POSTERIOR

Respostas

Grupo

\begin{tabular}{|c|c|c|c|c|c|}
\hline \multirow[b]{2}{*}{ Comportamentais } & \multirow[b]{2}{*}{ Nivel } & \\
\hline & & Anterior & $\begin{array}{l}\text { Situagão } \\
\text { Posterior }\end{array}$ & Anterior & Posterior \\
\hline Movimentar-se & $\begin{array}{r}\text { I } \\
\text { III }\end{array}$ & $\begin{array}{r}11 \\
7 \\
3\end{array}$ & $\begin{array}{l}7(\rightarrow) \\
5(\rightarrow) \\
8(\leftarrow)\end{array}$ & $\begin{array}{r}11 \\
8 \\
5\end{array}$ & $\begin{array}{r}11(=) \\
4(\rightarrow) \\
4(\rightarrow)\end{array}$ \\
\hline Olhar & $\underset{\text { III }}{\text { II }}$ & $\begin{array}{r}9 \\
11 \\
3\end{array}$ & $\begin{array}{l}4(\rightarrow) \\
4(\rightarrow) \\
9(-)\end{array}$ & $\begin{array}{r}10 \\
8 \\
7\end{array}$ & $\begin{array}{l}9(\rightarrow) \\
8(=) \\
6(\rightarrow)\end{array}$ \\
\hline $\begin{array}{l}\text { Expressar } \\
\text { emoçőes }\end{array}$ & $\begin{array}{r}\text { I } \\
\text { III }\end{array}$ & $\begin{array}{l}7 \\
2 \\
2\end{array}$ & $\begin{array}{l}2(\rightarrow) \\
1(\rightarrow) \\
8(\leftarrow)\end{array}$ & $\begin{array}{l}7 \\
1 \\
3\end{array}$ & $\begin{array}{l}6(\rightarrow) \\
2(=) \\
1(\rightarrow)\end{array}$ \\
\hline Verbalizar & $\begin{array}{l}\text { I } \\
\text { II } \\
\text { III }\end{array}$ & $\begin{array}{l}2 \\
3 \\
-\end{array}$ & $\begin{array}{l}1(\rightarrow) \\
1(-) \\
9(\leftarrow)\end{array}$ & $\begin{array}{l}\mathbf{4} \\
\mathbf{5} \\
\mathbf{3}\end{array}$ & $\begin{array}{l}2(\rightarrow) \\
4(\overrightarrow{)}) \\
3(=)\end{array}$ \\
\hline Brincar & III & - & $5(\leftarrow)$ & 一 & $1(\leftarrow)$ \\
\hline $\begin{array}{l}\text { Não responder a } \\
\text { um estímulo } \\
\text { ou solicitação }\end{array}$ & I & 4 & $-(\rightarrow)$ & 4 & $5(\leftarrow)$ \\
\hline
\end{tabular}

( =) Indica não variação da frequiência de crianças, entre as duas situações.

( - ) Indica aumento da frequência de crianças, entre as duas situações.

( $\rightarrow$ ) Indica diminuição da frequêencia de crianças, entre as duas situações.

Já a tabela 6, que se refere às crianças do grupo controle mostra que tanto na situação anterior, como na situação posterior, as subcategorias que apresentam maior freqüência de respostas comportamentais são: movimenta partes do corpo, manipula roupas ou objetos e muda de posição, todas no Nível I. No total, vê-se que as respostas de Nível I permanecem sendo a grande maioria em ambas as situações e que há um decréscimo das respostas de Nível III na situação posterior, que passam a ser a maioria nesta situação de observação.

Comparando-se as tabelas 7 e 8 vemos que, de acordo com a primeira, das 11 crianças as quais compuseram o grupo experimental, 10 delas apresentam um decréscimo de freqüência de respostas comportamentais de Nivel I, sendo que 4 delas deixam de apresentá-los, e um acréscimo de respostas comportamentais de Nivel III, na situação pos- 


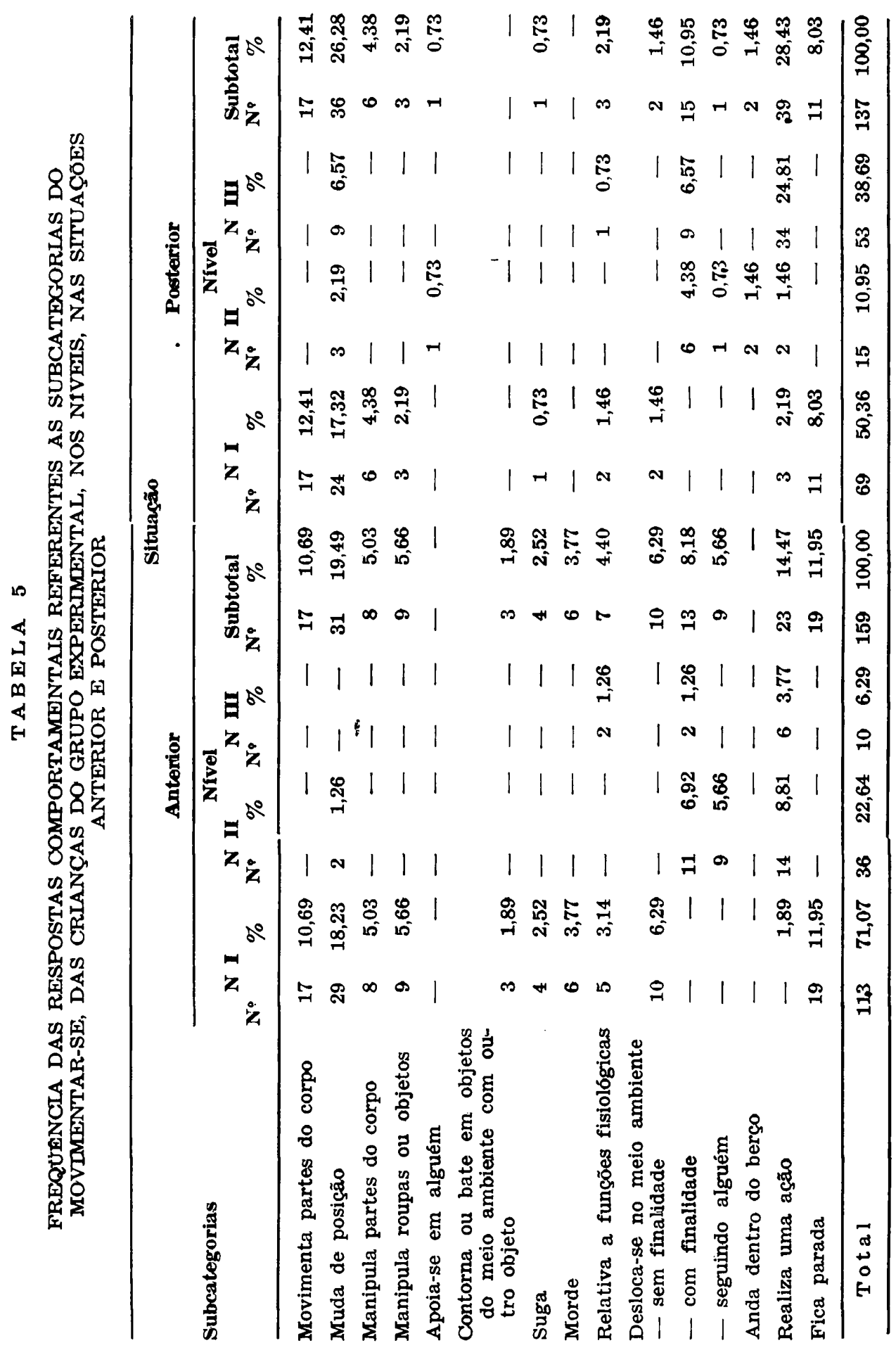




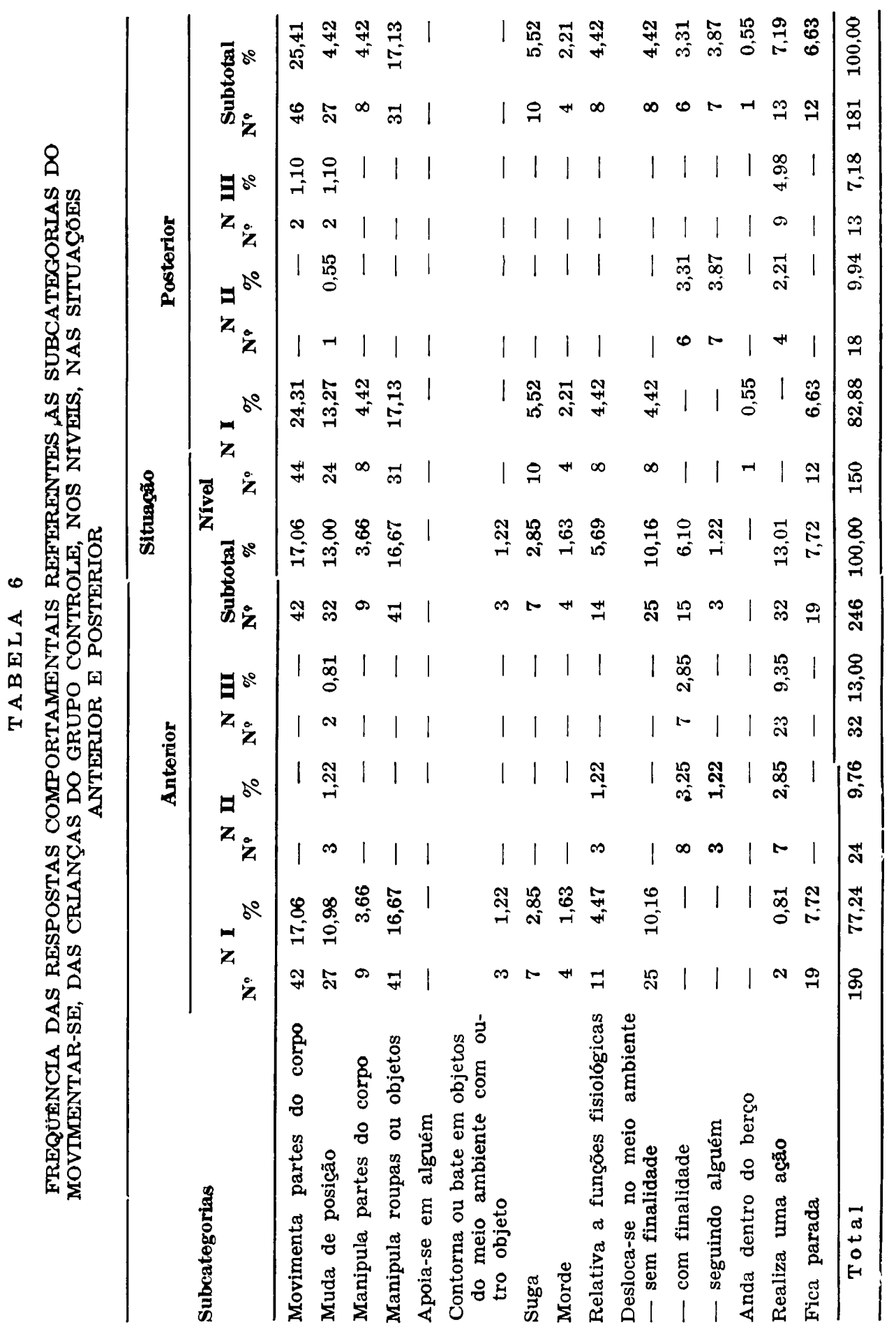




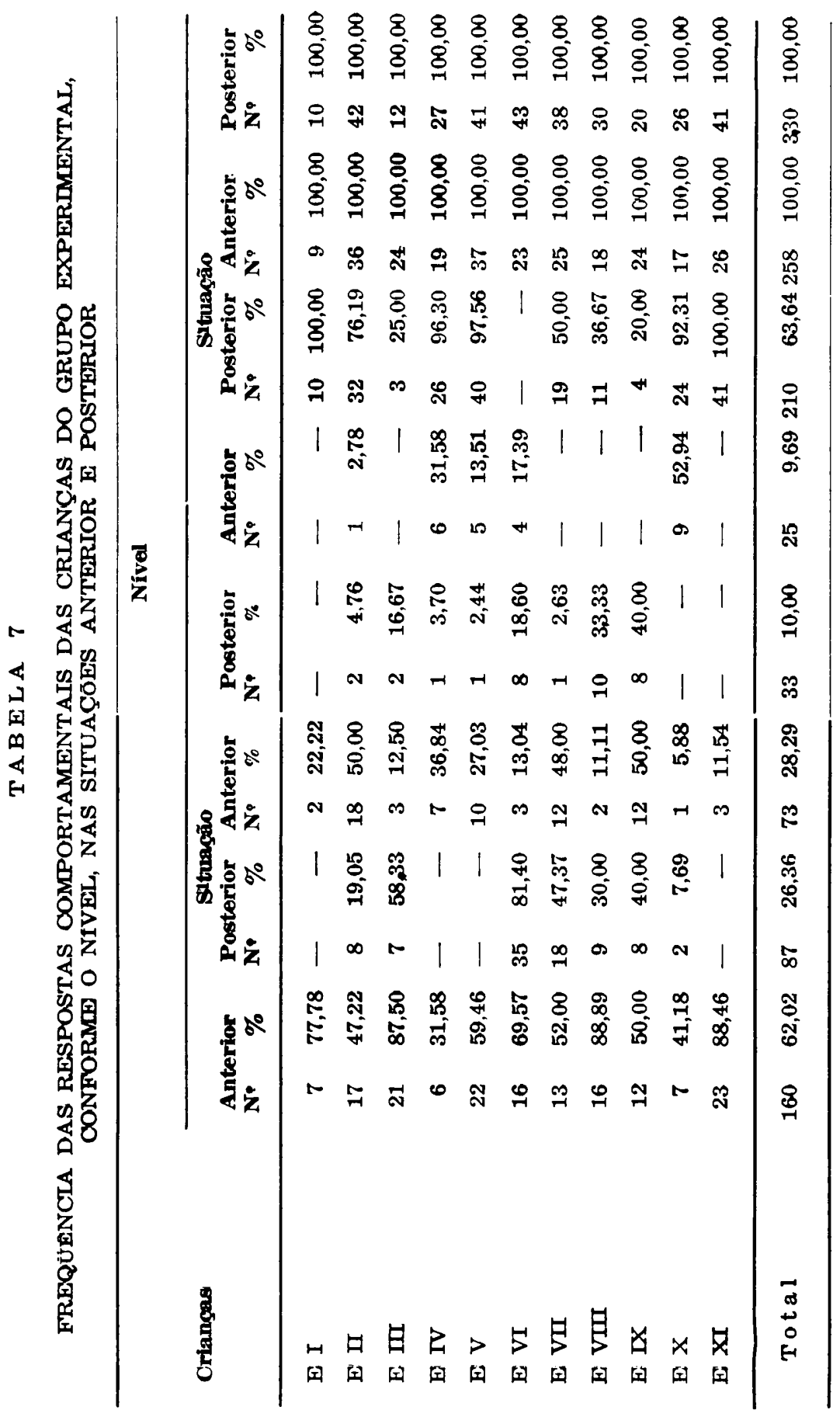




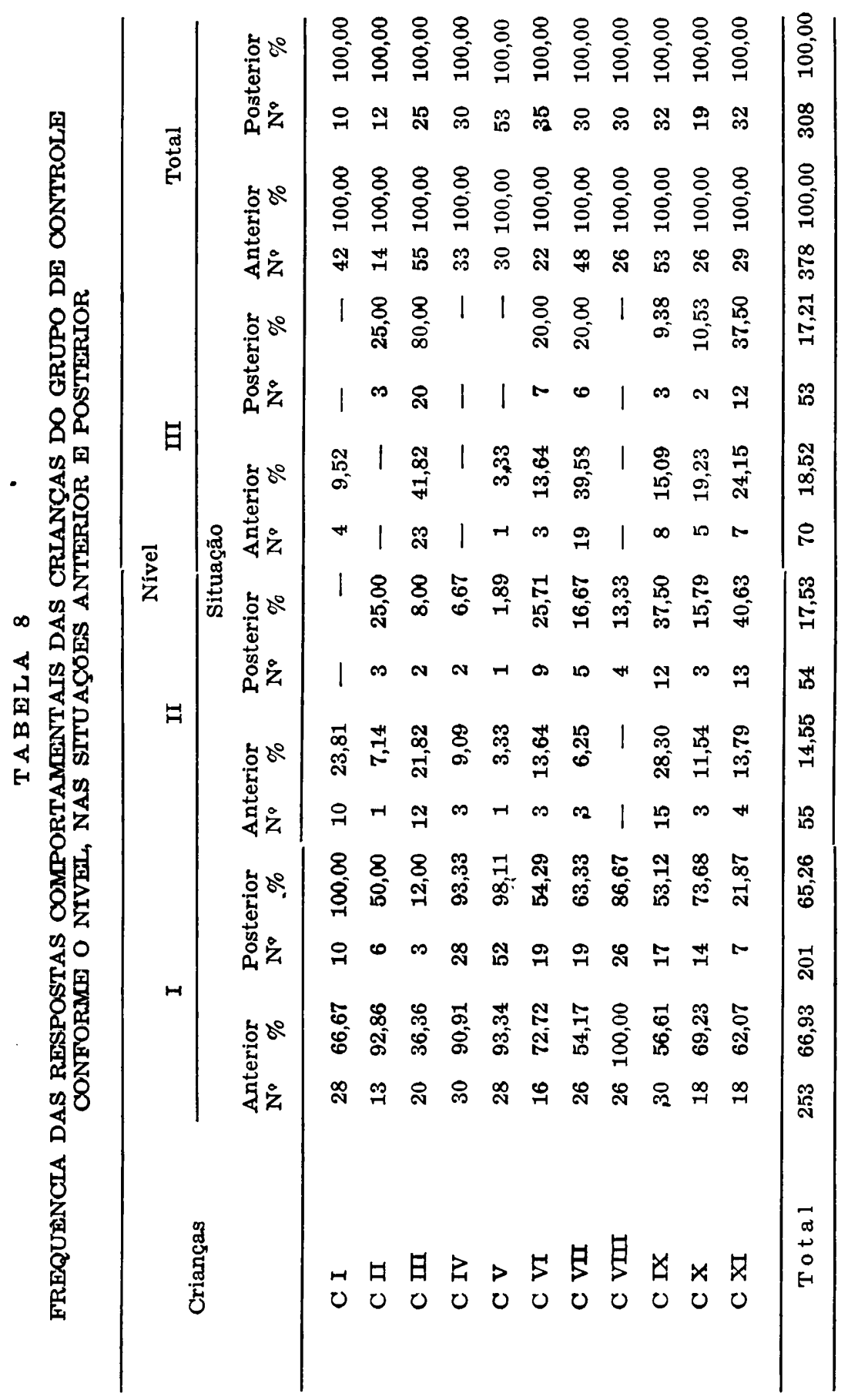




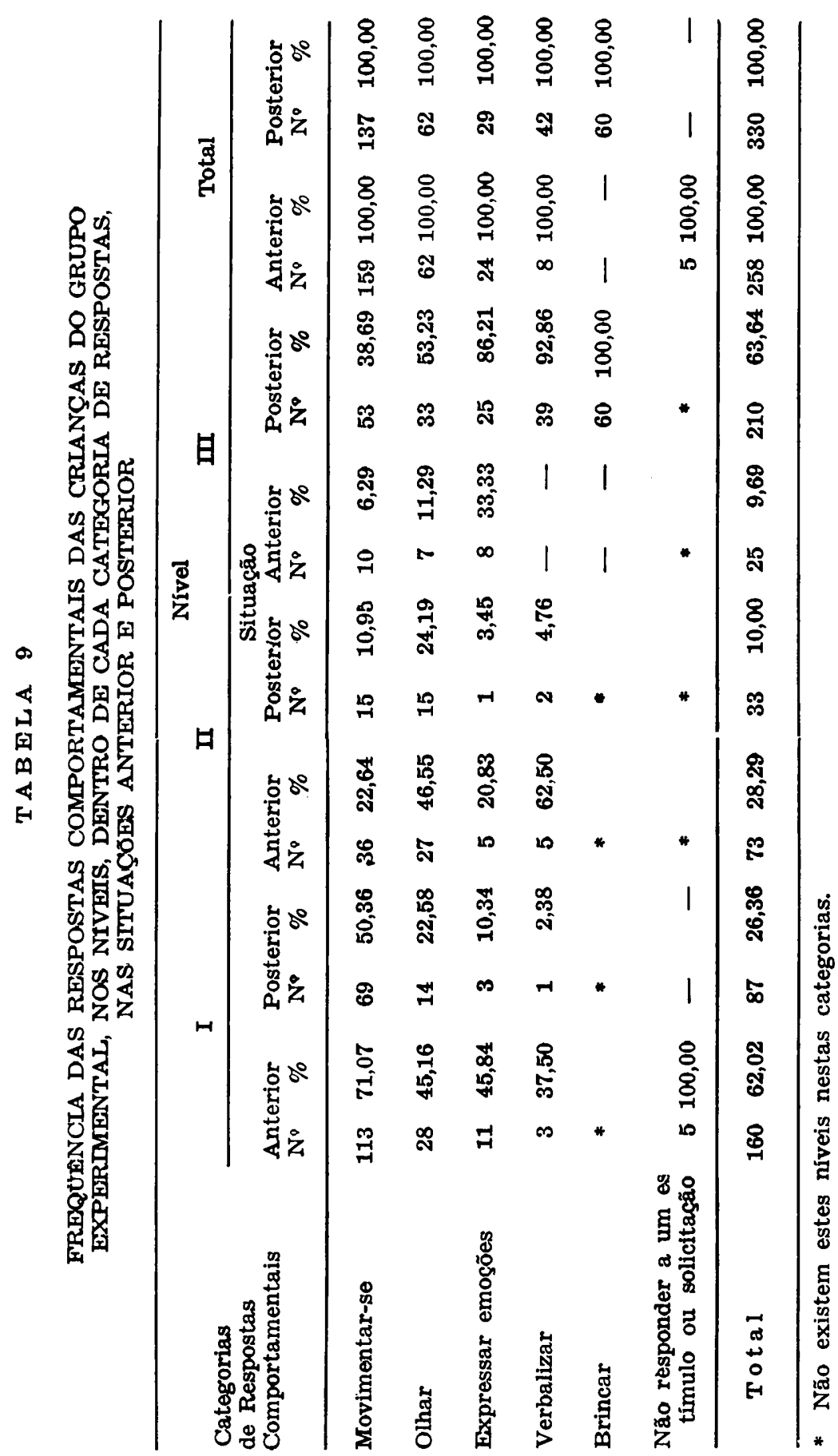




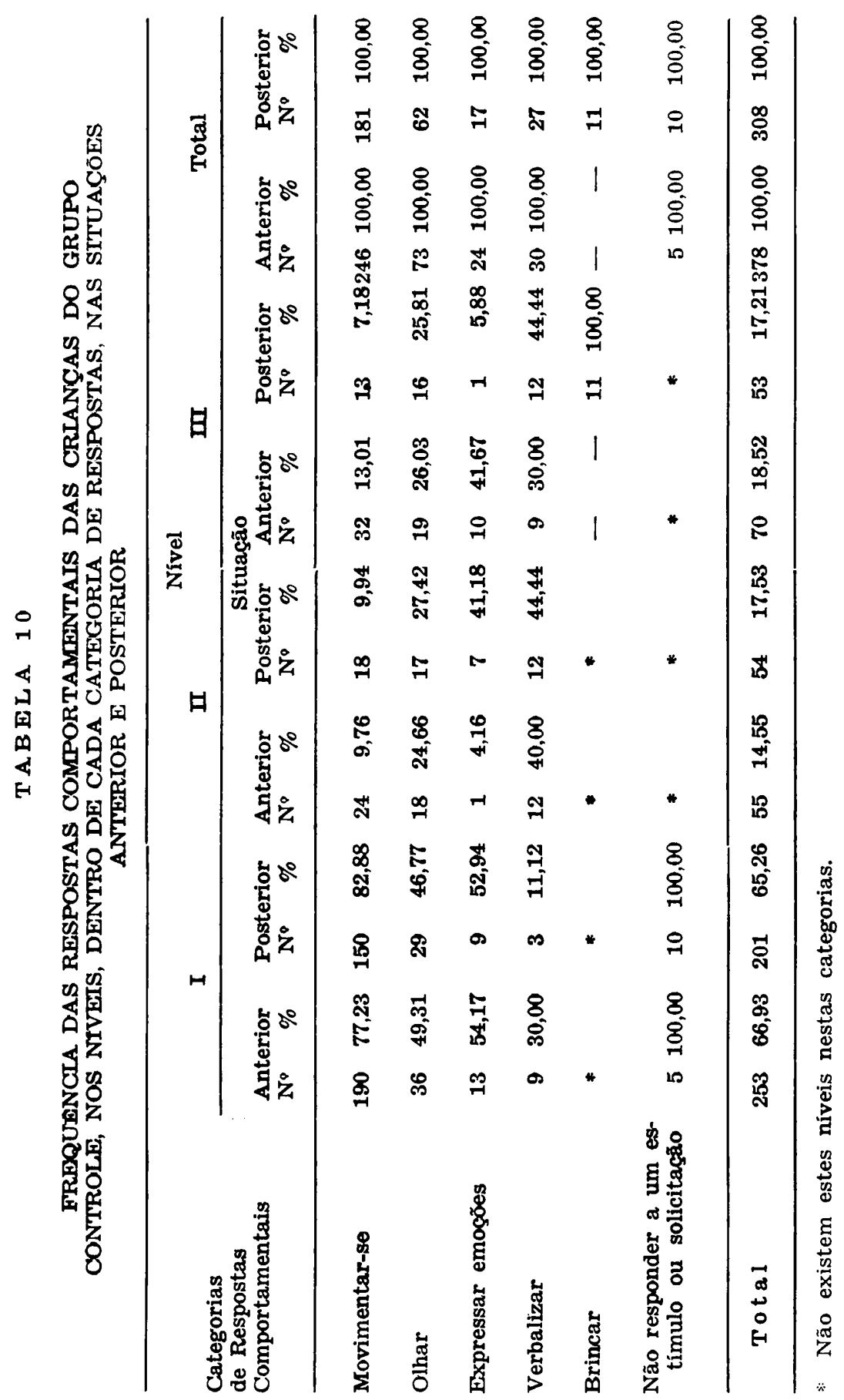


terior, sendo que 6 delas não as apresentavam na situação anterior. Vemos também que as variações de freqüência relativa são, em sua maioria, bastante significativas, e que na situação anterior a maioria das crianças ( 7 delas) mantinha a maior freqüência de suas respostas comportamentais no Nivel $I$, enquanto que na situação posterior a maioria delas (8 das mesmas) passa a apresentar a maior freqüência de suas respostas comportamentais no Nivel III.

Já a tabela 8, que se refere às crianças do grupo controle, permite-nos verificar que as variações de frequiência relativa ocorridas entre as situações anterior e posterior são, em sua maioria, muito menos significativas que as apresentadas pelas crianças do outro grupo e que em ambas as situações a maioria das crianças do grupo controle mantém a maior freqüência de suas respostas comportamentais no Nível I (10 crianças na situação anterior e 9 na situação posterior).

Verifica-se, conforme a tabela 9, que no grupo experimental, na situação posterior, há um decréscimo na freqüência de todas as categorias de respostas comportamentais que são de Nivel I e Nivel II e um aumento das de Nível III, e que as variações de frequiência são, em geral, bastante acentuadas.

Já no grupo controle, tabela 10 , a situação é outra. Vemos que apenas nas categorias brincar e verbalizar verifica-se acréscimo de freqüência no Nível III e que em geral, as variações de freqüência relativa são pouco acentuadas, sendo que a grande exceção refere-se a brincar, no Nivel III, cujo acréscimo é de $100 \%$; isto se justifica uma vez que todas as respostas comportamentais desta categoria são desse nível e podemos lembrar que foram apresentadas por apenas 1 criança (conforme a tabela 4).

A diferença constatada entre os comportamentos de interação interpessoal e as respostas comportamentais das crianças dos grupos experimental e controle, nas situações anterior e posterior, mostra que a participação das crianças de 3 a 5 anos, recém-hospitalizadas em uma sessão de brinquedo terapêutico junto à enfermeira, favorece a modificação de seu comportamento, e que existe diferença entre o comportamento daquelas que têm oportunidade de participar desta sessão e daquelas que não têm essa oportunidade.

Comparando-se as características das respostas comportamentais de Nivel III com trabalhos de diversos autores entre os quais CALKIN ${ }^{3}$, DENYES ${ }^{5}$, GOHSMAN ${ }^{8}$, GERHART ${ }^{7}$, vemos que elas são compativeis a comportamentos descritos como sendo de adaptação, de ego forte e apropriados ao desenvolvimento esperado da criança nesta faixa etária. Isto indica que, após brincarem, as crianças do grupo experimental parecem ter apresentado uma evolução positiva de seu comportamento.

Através do Gráfico 1, pode-se comparar os totais de freqüência relativa de respostas comportamentais dos três niveis, na situação anterior e posterior, ilustrando a diferença desses resultados entre as crianças dos grupos experimental e controle. 


\section{GRÁFICO 1}

Frequência do total de respostas comportamentais das crianças dos grupos experimental e controle, nos níveis, nas situações anterior e posterior

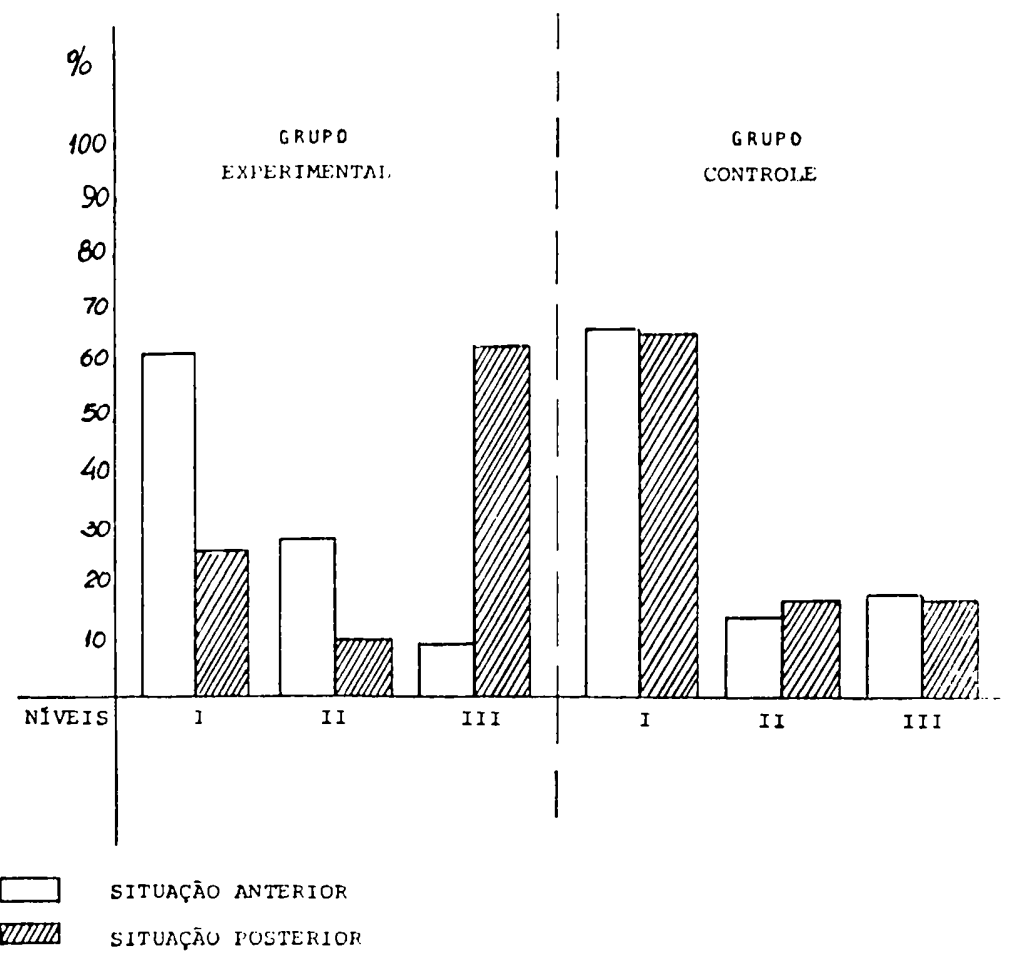

\section{IV - CONCLUSOES}

1. As crianças do grupo experimental apresentaram, após participarem da sessão de brinquedo terapêutico, as seguintes modificações em seu comportamento:

- passaram a interagir mais com as outras pessoas e a iniciarem mais estas interações;

- houve um aumento na freqüência de crianças que apresentaram respostas comportamentais de Nivel III, em todas as categorias das respostas;

- na categoria Movimentar-se, a maior freqüência passou a ser da subcategoria realiza uma ação, no Nível III, enquanto na situação anterior era da subcategoria muda de posição, no Nivel I;

- a grande maioria das crianças apresentou um decréscimo na freqüência de respostas comportamentais de Nivel I e um aumento desta freqüência no Nível III, passando também a apresentar a maior freqüência de suas respostas comportamentais neste nível; 
- em todas as categorias de respostas comportamentais houve um significativo decréscimo na freqüência de respostas comportamentais de Nivel I e um significativo aumento desta freqüência no Nivel III;

- no total as respostas comportamentais de Nivel III passaram a ser a maior $(63,64 \%)$, enquanto as de Nivel I passaram a corresponder à minoria $(9,69 \%)$ das respostas comportamentais apresentadas pelas crianças desse grupo de estudo.

2. As crianças do grupo controle, que não tiveram a oportunidade de brincar, também passaram a apresentar na situação posterior, maior freqüência de comportamentos com interação interpessoal, mas isto se deveu ao acréscimo na freqüência das interações iniciadas por outra pessoa, havendo inclusive decréscimo daquelas em que a criança iniciou a interação. No demais, elas mantiveram características semelhantes às verificadas na situação anterior, com variações na freqüência pouco significativas, sendo que no total, a maioria delas permaneceu no Nível I. 3. Considerando-se as características das respostas comportamentais de Nivel III, que na situação posterior passaram a ser a maioria entre as crianças do grupo experimental, pode-se inferir que o brinquedo terapêutico favoreceu o aparecimento de comportamentos mais compatíveis ao desenvolvimento esperado nesta faixa etária, assim como os considerados de adaptação ou de ego forte.

RIBEIRO, C.A. The effect if therapeutic-play, used by pediatric-nurse, on the behavior of children recently hospitalized. Rev Esc. Enf. USP, v. 25, n. 1, p. 41-60, apr. 1991.

This work describes the realization and the results of one experimental research accomplished with children from 3 to 5 years of age, recently-hospitalized using the therapelitic-play. The results showed that it helped children behave more according to what is expected of this 3-5 age group, as well as show signs that they had adapted or presented ego strenght.

UNITERMS: Playthings. Child hospitalized. Pediatric nursing.

\section{REFERENCIAS BIBLIOGRÁFICAS}

1. AXLINE, V.M. Ludoterapia: a dinamica interior da criança. Belo Horizonte, Interlivros, 1972.

2. BARTON, P.F. Play as a tool os nursing. Nurs. Outlook, v. 10, n. 3, p. 162-4, 1962.

3. CALKIN, J.D. Are hospitalized toddlers adapting to the experience as well as wo think? MCN, v. 4, n. 18-23, 1979.

4. CLATWORTH, S.M. The effect of therapeutic play on the anxiety behavior of hospitalized children. Ann Arbor, University Microfilms International, 1978. 226 p. (Doctoral Degree) - Boston University Scholl of Education.

5. DENYS, M.J. A child with Hirchsprung's disease uses a nurse to gain ego strenght. In: AMERICAN NURSES ASSOCIATION. Ana Clinical Sessions: 1968. New York, Appleton - Century - Crofts, 1968. D. 155-61.

6. ERICKSON, F. Reactions of children to hospital experience. Nurs. Outlook, v. 6, n. 9, p. 501-4, 1958. 
7. GFRFART, S.M. A preschool child's use of language in coping with hospitallzation. Matern. Child. Nurm. J., v. 8, n. 1, p. 39-47, 1979.

8. GoHsman, B. The hospitalized child and the need for mastery. Issues Compr. Pediatr. Nurs., v. 5, n. 2, p. 67-76, 1981.

9. GREEN, C.S. Larry thought puppet play «childish» but it helped him face his fears. Nursing, v. 5, n. 3, p. 30-3, 1975.

10. Understanding children's needs through therapeutic play. Nursing, v. 4, n. 10, p. 31-2, 1974.

11. JUNKER,D apud GREEN, C.S. Understanding chlldren's needs through therapeutlc play. Nursing, v. 4, n. 10, p. 31-2, 1974 .

12. KENNY, T.J. The hospitalized child. Pediatr. Clin. North Am, v. 22, n. 3, p. 583-93, 1975.

13. KUM, B.; ILGEN, N. Hospitalization of the child-part II. Turk. J. Pediatr., v. 19, n. 3/ 4. D. 108-17, 1977.

14. MACHADO, D.V.M. O brinquedo e suas funçoses. An. Nestlé, n. 100, p. 54-8, 1977.

15. \& MACHADO, E.M. Culdados psicológicos à criança hospitalizada. Rev. Hosp. Clin., v. 11, n. 4, p. 202-8, 1956.

16. MARLOW, D. Textbook of pediatric nursing. 5 ed. Philadelphla, Saunders, 1977. cap. 5, p. 73-112: The nurse and the 111 child.

17. MARTINS, D.M.R. et al. Assistência de enfermagem a crianças hospitalizadas quando enfrentam situaçōes desagradáveis - parte I. Kev. Esc. Enf. USP., v. 13, n. 2, p. 157-69, 1979.

18. et al. Assistência de enfermagem a crianças hospitalizadas quando enfrentam situações desagrađáveis - parte II. Rev. Esc. Enf. USP., v. 13, n. 3, p. 287-99, 1979.

19. MORAES, E. Manifestações de tensão e comportamento de adaptação de crianças hospitalizadas. Rev. Esc. Enf. USP., v. 5, n. 1, p. 44-57, 1971.

20. - Mensagem única, um modo terapêutico de tratar crianças em sofrimento: relato de uma experiência. Rev. Esc. Enf. USP., v. 14, n. 2, p. 165-9, 1980.

21. - et al. Estudantes de enfermagem assistem crianças doentes, utilizando «entrevista com brincadeira», Kev. Esc. Enf. ESP., v. 13, n. 1, p. 29-39, 1979.

22. PRUGH, D.H.A. Study of the emotional reactions of children and familieg to hospitallzations and illness, Am. J. Orthopsychiatry, v. 23, n. 1, p. 70-106, 1953.

23. RAMSEY, N.L. Effects of hospitalization on the child and the family. In: SMITH, M.J. et. al. Child and family concepts of nursing practice. New York, McGraw-Hill, 1982, cap. 16 p. 317-41.

24. RIBEIRO, C.A. Sentíndo o valor das experiências significativas para a aprendizagem: relato de duas situações vividas com crianças hospitalizadas. Rev. Esc. Enf. USP., v. 17. n. 3, p. 179-203, 1983.

25. ROBERTSON, J. Some responses of young children to loss of maternal care. Nure. Times, v. 49 , n. 16, p. $382-6,1953$.

26. SABOYA, B. No universo da criança, brincar é ir em frente. O GLOBo. Rlo de Janelro, 6 out. 1985. Jornal da Familia, p. 1.

27. WHALEY, L.F.; WONG, D.L. Essentials of pediatric nursing. Saint Louis, Mosby 1982. $943 \mathrm{p}$.

28. WOLTMAN, A.G. Therapeutic play techniques - 9o concepts of play therapy techniques. Am. J. Orthopsychiatry, v. 25, n. 4, p. 771-83, 1955. 


\section{A NEXO 1}

Fotos de brinquedos usados na Sessão de Brinquedo Terapêutico
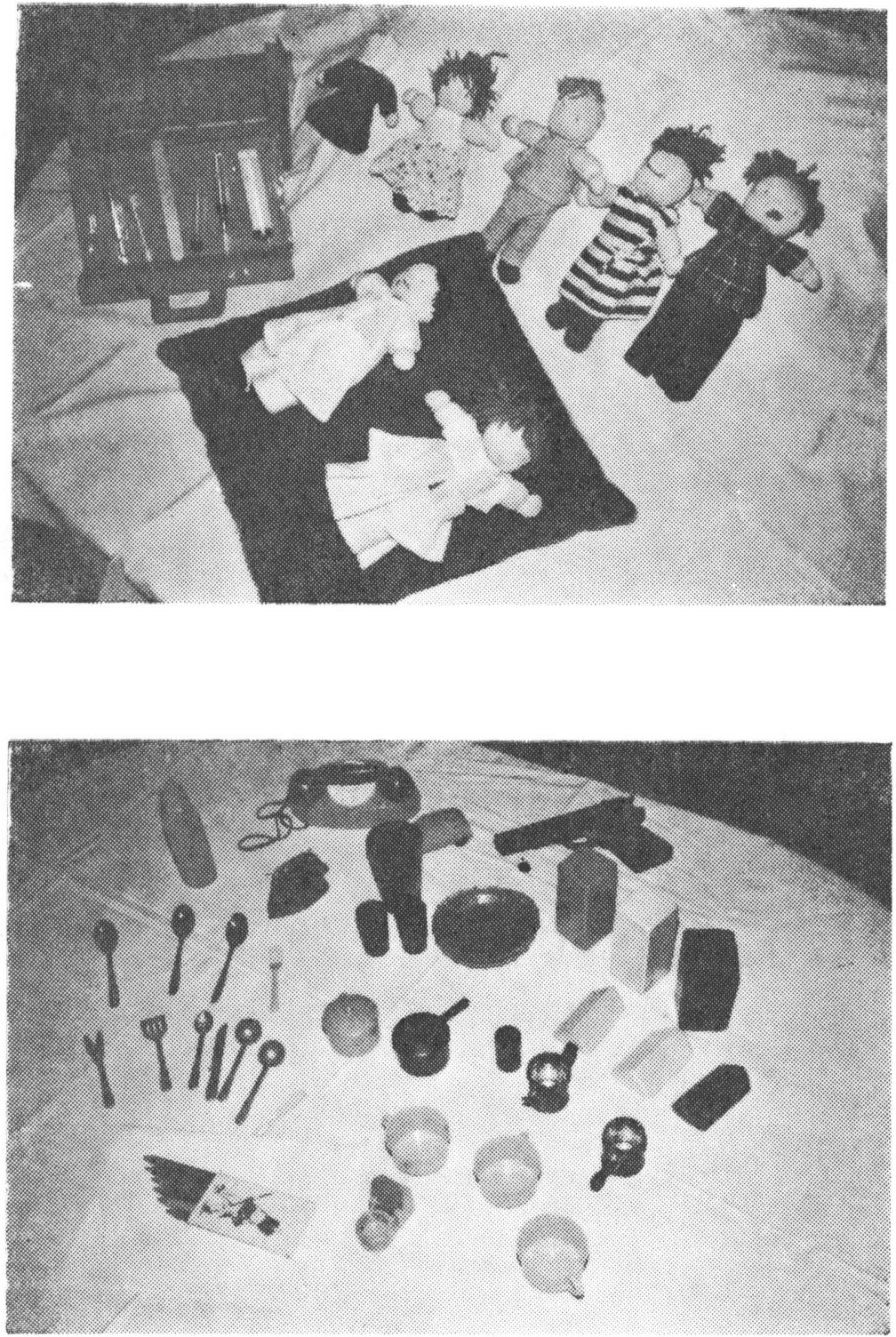